
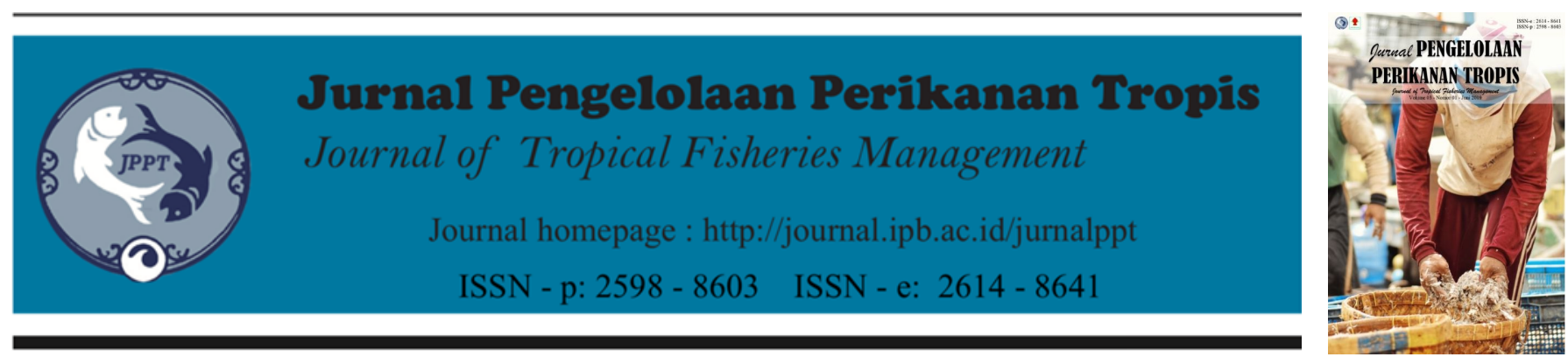

\title{
Reproduksi Ikan Kembung Lelaki (Rastrelliger kanagurta Cuvier, 1816) Kaitanya Dengan Suhu Permukaan Laut Di Perairan Selat Sunda
}

\author{
(Reproduction of Indian Mackerel (Rastrelliger kanagurta Cuvier, 1816) relation to Sea Surface \\ Temperature in Sunda Strait Waters)
}

\section{Muhammad Luthfi Alif Putera*, Isdrajad Setyobudiandi}

Departemen Manajemen Sumberdaya Perairan, Fakultas Perikanan Dan Ilmu Kelautan, Institut Pertanian Bogor Jl. Agatis, Kampus IPB Dramaga, Bogor, Jawa Barat, Indonesia

\section{ARTIKEL INFO}

Article History

Recevied: 25 Februari 2019

Accepted: 20 Mei 2019

\section{Kata Kunci:}

Ikan kembung lelaki, reproduksi,

Selat Sunda, Suhu

Keywords:

Indian mackerel, reproduction, Sunda

Strait, sea surface temperature

\section{ABSTRAK}

Ikan kembung lelaki merupakan ikan ekonomis penting yang banyak dinikmati masyarakat. Tingkat permintaan yang beresiko menurunkan ketersediaan stok dan dapat menggangu kemampuan reproduksi. Penelitian ini bertujuan untuk menganalisis aspek biologi reproduksi ikan kembung lelaki (Rastrelliger kanagurta) yang dipengaruhi suhu permukaan air laut di daerah penangkapan ikan perairan Selat Sunda. Penelitian dilaksanakan pada bulan Mei hingga September 2018. Data primer yang diperoleh dengan menggunakan teknik Penarikan Contoh Acak Berlapis (PCAB). Total ikan yang diambil selama penelitian sebanyak 546 ekor. Nisbah kelamin ikan kembung lelaki senilai 1:0,65 dengan dominansi ikan jantan. Fekunditas ikan kembung lelaki berkisar pada 2314-96924 butir telur dengan rata-rata 24075 butir telur. Puncak pemijahan ikan kembung lelaki pada bulan Juli dan Agustus dengan tipe pemijahan partial spawner. Ikan kembung lelaki jantan mencapai ukuran pertama kali matang gonad (Lm) pada ukuran 193,8 mm dan betina 177,9 mm. Pola kematangan gonad ikan selama per 6 bulan dipengeruhi oleh nilai suhu permukaan laut.

\section{Korespondensi Author}

Muhammad Luthfi Alif Putera, Departemen Manajemen Sumberdaya Perairan, Fakultas Perikanan Dan Ilmu Kelautan, Institut Pertanian Bogor

Email: luthfialifputera@gmail.com

\section{ABSTRACT}

Indian mackerel is an important economic value. The high level of demand leads to an increase in excessive fishing activities without regard to the biological aspects of the species. The purpose of this research is analyze the reproductive aspects of indian mackerel (Rastrelliger kanagurta) which are influenced by sea surface temperatures in the fishing areas of the Sunda Strait waters. The research was conducted from May to September 2018. Primary data were obtained using the Stratified Random Sampling. The total fish taken during the research were 546. The sex ratio of indian mackerel is worth 1: 0.65 with the dominance of male. The fecundity of indian mackerel ranges from 2314-96924 eggs with an average of 24075 eggs. Peak spawning of indian mackerel in July and August with a partial spawner spawning type. male indian mackerel reaches the first size of mature gonads (Lm) at $193.8 \mathrm{~mm}$ and females 177.9 $\mathrm{mm}$. Trend of gonad maturity indian mackerel fish for 6 months is influenced by the value of sea surface temperature.

\section{PENDAHULUAN}

Selat Sunda merupakan daerah penangkapan yang memiliki sumberdaya ikan yang tinggi, letaknya berada di ujung Pulau Jawa dan ujung selatan Pulau Sumatera yang masuk ke dalam wilayah pengelolaan perikanan (WPP-RI) 572. Selat Sunda merupakan salah satu perairan yang memiliki potensi perikanan besar di Indonesia, baik perikanan pelagis maupun demersal. Hasil tangkapan nelayan yang berasal dari Provinsi
Lampung dan Banten ditangkap di wilayah perairan Selat Sunda sebagian besar didaratkan di Pelabuhan Perikanan Pantai (PPP) Labuan (Permatachani et al. 2016) dan Lempasing. Ikan kembung lelaki merupakan ikan pelagis kecil yang memiliki nilai potensial dan dapat ditemukan diseluruh perairan Indonesia. Ikan kembung lelaki merupakan hasil tangkapan nelayan yang memiliki nilai ekonomis penting di Indonesia (Sarasati 2017). Hal ini disebabkan spesies ini banyak ditangkap untuk dikonsumsi 
karena memiliki tekstur daging yang padat dan mengandung nilai gizi yang tinggi dan memiliki nilai jual yang menguntungkan dibandingkan ikan pelagis lainya (Permatachani et al. 2016). Ikan kembung lelaki merupakan ikan ekonomis penting dan dengan tingkat permintaan yang tinggi cenderung terjadinya peningkatkan aktivitas penangkapan yang berlebih tanpa memperhatikan aspek biologis spesies. Tingginya tingkat pemanfaatan dan kemungkinan tingkat eksploitasi yang tinggi terhadap sumberdaya ikan ini, menuntut upaya pengelolaan yang baik agar pemanfaatan ikan secara lestari (Ibrahim et al. 2018).

Upaya pengeloaan perlu dilakukan untuk menjamin kelestarian sumberdaya ikan kembung lelaki oleh karena itu melalui pendekatan aspek biologi reproduksi karena hal ini menjadi bagian komponen yang mendasar dan penting terkait karateristik biologis sumberdaya ikan bagi pengelolaan untuk mendukung penyusunan opsi perlindungan ikan yang sedang dan akan memijah. Penangkapan ikan secara eksploitasi dapat menekan sumberdaya stok ikan dan kondisi habitat. Variabilitas suhu permukaan air laut dan sebaran klrofil-a menurut Wang (2014) efek dari suhu dapat mempengaruhi biologis ikan yang rentan terhadap usaha penangkapan. Keterkaitan suhu dan klorofil-a di perairan merupakan faktor fisik yang utama dalam kehidupan ikan dan dapat memberikan efek dan mempengaruhi semua proses reproduksi dari pematangan gonad, perkembangan larva dan juvenil serta kelangsungan hidup spesies ikan (Pankhurst dan Munday 2011).

Perubahan iklim akan sangat berpengaruh terhadap fisiologi dan tingkah laku individu, populasi maupun komunitas. Kondisi ekstrim dengan naiknya suhu permukaan air laut, rendahnya konsentrasi oksigen terlarut dan $\mathrm{pH}$ air dapat mengakibatkan kematian pada ikan. Lingkungan dengan kondisi yang ekstrem akan mengambat pertumbuhan dan pola reproduksi ikan. Semua perubahan ini secara langsung berpengaruh pada populasi dan struktur komunitas ikan, yang pada akhirnya berpengaruh pada stok perikanan (Syahailatua 2008). Ekosistem laut tidak dalam keadaan stabil akan tetapi dipengaruhi oleh lingkungan yang memiliki tingkat variasi pada skala spasial dan temporal.

Pemahaman tentang biologi reproduksi suatu spesies merupakan prasyarat penting untuk memberikan saran ilmiah bagi pengelolaan perikanan agar tetap lestari dan berkelanjutan. Sehingga stok ikan tidak mengalami kepunahan dan mencegah terjadinya tekanan penangkapan yang mempengaruhi daur hidup ikan.

\section{BAHAN DAN METODE}

\section{Waktu dan Lokasi}

Penelitian dilaksanakan pada bulan Mei hingga September 2018. Pengambilan contoh dilakukan setiap satu bulan sekali. Sampel ikan yang diambil merupakan hasil tangkapan nelayan di perairan Selat Sunda yang didaratkan di PPP Labuan, Banten dan PPP Lempasing, Lampung (Gambar 1). Analisis dilakukan di Laboratorium Biologi Perikanan Departemen Manajemen Sumberdaya Perairan, Fakultas Perikanan dan Ilmu Kelautan, Institut Pertanian Bogor.

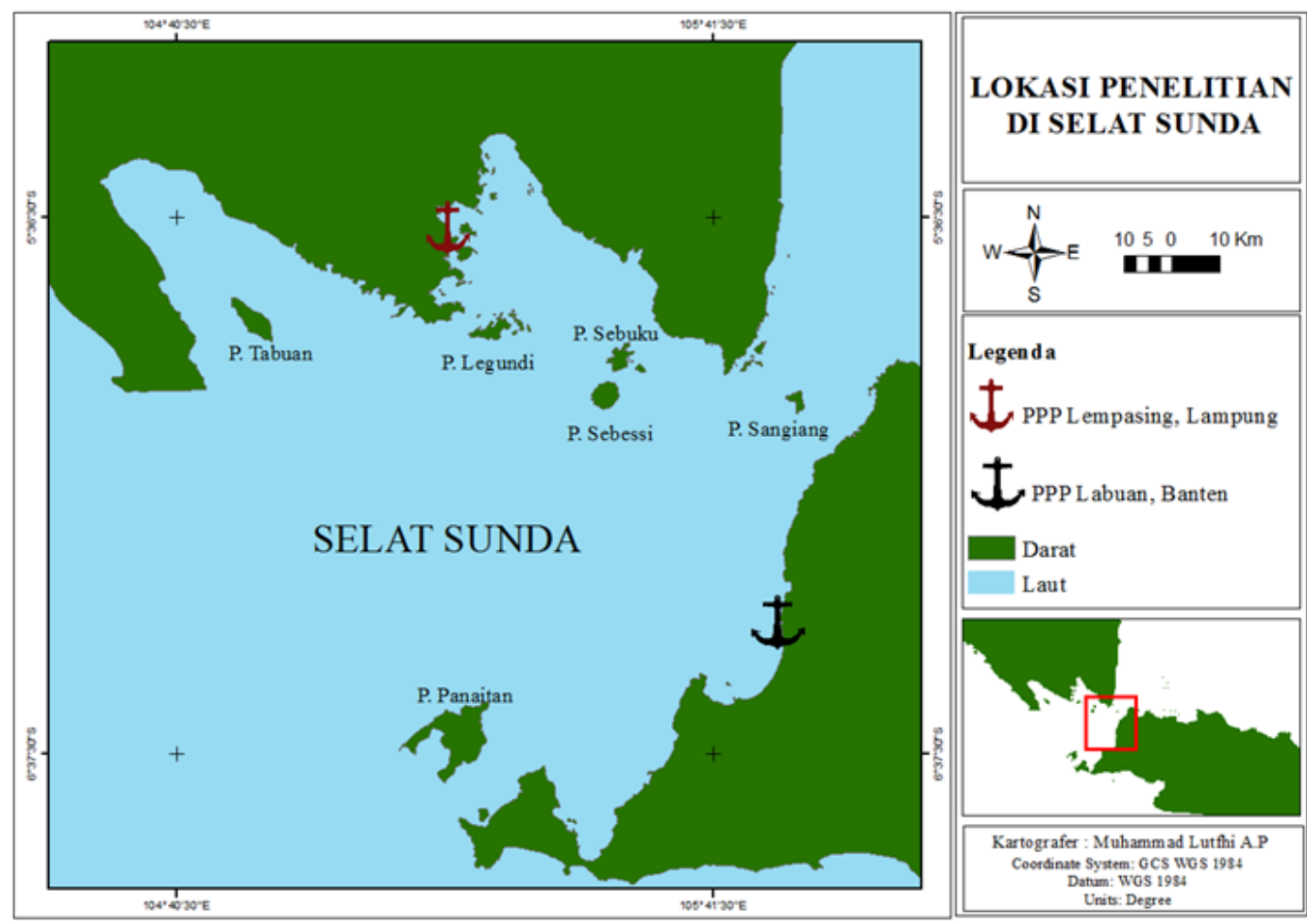

Gambar 1 Lokasi penelitian dan daerah penangkapan ikan kembung lelaki 


\section{Pengumpulan data}

Penelitian ini menggunakan data primer dan data sekunder yang dikumpulkan melalui sampling atau observasi langsung di lapang, analisis laboratorium, penginderaan jauh melalui satelit dan pengambilan data dari instansi terkait. Data primer yang diperoleh dengan menggunakan teknik Penarikan Contoh Acak Berlapis (PCAB). Ikan contoh yang diambil terdiri dari tiga lapisan yaitu ukuran kecil, sedang, dan besar. Pengumpulan data primer meliputi pengukuran morfometrik ikan, identifikasi jenis kelamin dan tingkat kematangan gonad, pembedahan sampel ikan unuk mendapatkan organ dalam berupa gonad dan usus. Selanjutnya akan dianalisis lebih lanjut di laboratorium untuk menghitung jumlah telur dan identifikasi komposisi makanan. Data sekunder yang digunakan yaitu data sebaran suhu permukaan laut di perairan Selat Sunda yang diakses melalui http://oceancolor.gsfc.nasa.gov/.

\section{Analisis Data}

\section{Fekunditas}

Metode gravimetri saat ini merupakan metode yang paling umum digunakan untuk memperkirakan fekunditas, ditentukan dengan berat gonad dan berat gonad contoh, dengan membagi 3 sub sampel gonad dan diketahui beratnya. Setiap sub sampel ditimbang dengan ketelitian hingga $0,001 \mathrm{~g}$. dari masing masing sub sample dihitung jumlah telurnya (oocyte) dan analisis perhitungan fekunditas berdasarkan (Murua et al. 2003) adalah sebagai berikut.

$$
\mathrm{F}=\left(\frac{\mathrm{G}}{\mathrm{Q}}\right) \mathrm{X} \mathrm{N}
$$

Keterangan:

$$
\begin{array}{ll}
\mathrm{F} & =\text { fekunditas (butir) } \\
\mathrm{G} & =\text { berat gonad }(\mathrm{g}) \\
\mathrm{Q} & =\text { berat gonad contoh }(\mathrm{g}) \\
\mathrm{N} & =\text { jumlah telur tiap gonad contoh (butir) }
\end{array}
$$

\section{Tingkat kematangan gonad}

Tingkat kematangan gonad merupakan pengelompokan kematangan gonad ikan berdasarkan perubahan-perubahan yang terjadi pada gonad. Perkembangan gonad yang semakin matang merupakan bagian dari reproduksi ikan sebelum terjadi pemijahan. Masing-masing spesies ikan waktu pertama kalinya gonad menjadi matang tidak memiliki ukuran yang sama. Pengamatan kematangan gonad dilihat secara morfologi berdasarkan penelitian Ganga (2010) yang disajikan pada Tabel 1.

\section{Indeks kematangan gonad}

IKG adalah perbandingan dari berat gonad terhadap tubuh ikan. Nilai IKG sebenarnya bisa dijadikan untuk penentuan tingkat kematangan gonad karena peningkatan IKG akan terjadi seiring dengan meningkatnya tingkat kematangan gonad ikan tersebut. Penentuan IKG dilakukan secara kuantitatif menurut (Ningrum et al. 2015) sebagai berikut.

$$
\mathrm{IKG}=\frac{B G}{B T} x 100 \%
$$

Keterangan:

$$
\begin{array}{ll}
\mathrm{BG} & =\text { Berat gonad }(\mathrm{g}) \\
\mathrm{BT} & =\text { Berat total }(\mathrm{g})
\end{array}
$$

\section{Ukuran pertama kali matang gonad}

Metode yang digunakan untuk mengetahui ukuran pertama kali matang gonad adalah Metode Spearman-Karber. Ukuran ikan pertama kali matang gonad dapat dihitung menggunakan rumus sebagai berikut (Udupa 1986):

$$
\mathrm{m}=\left[\mathrm{x}_{\mathrm{k}}+\left(\frac{\mathrm{x}}{2}\right)\right]-\left(\mathrm{x} \sum \mathrm{p}_{\mathrm{i}}\right)
$$

dengan,

$$
\mathrm{Lm}=\operatorname{antilog} \mathrm{m}
$$

dan selang kepercayaan 95\% untuk log m sebagai berikut:

$$
\text { antilog } m\left(m \pm 1,96 \sqrt{x^{2} \sum \frac{p_{i} \times q_{i}}{n_{i}-1}}\right)
$$

Keterangan:

$\mathrm{m}=\log$ panjang ikan pada kematangan pertama; $\mathrm{x}_{\mathrm{k}}=\log$ nilai tengah kelas panjang terakhir ikan

Tabel 1 Penentuan TKG secara morfologis (Ganga 2010)

\begin{tabular}{|c|l|l|}
\hline TKG & \multicolumn{1}{|c|}{ Betina } & \multicolumn{1}{|c|}{ Jantan } \\
\hline I & $\begin{array}{l}\text { Gonad berukuran kecil, berwarna merah muda, } \\
\text { telur tidak terlihat }\end{array}$ & $\begin{array}{l}\text { Gonad berukuran kecil, berwarna } \\
\text { keputihan, merata }\end{array}$ \\
\hline II & $\begin{array}{l}\text { Bentuk gonad tubular, berwarna kuning atau } \\
\text { oranye, mengisi setengah dari rongga perut, }\end{array}$ & $\begin{array}{l}\text { Gonad berwarna merah muda, keputihan } \\
\text { mengisi setengah dari rongga perut }\end{array}$ \\
\hline III & $\begin{array}{l}\text { Gonad berwarna oranye gelap, besar, mengisi } \\
\text { rongga tubuh, telur transparan dan terlihat }\end{array}$ & Gonad putih, besar, mengisi rongga tubuh \\
\hline IV & Gonad lembek, berwarna coklat kemerahan & Gonad lembek, berwarna putih kecoklatan \\
\hline
\end{tabular}


ikan telah matang gonad; $\mathrm{x}=\log$ pertambahan panjang pada nilai tengah; $p_{i}=$ proporsi ikan matang gonad pada kelas panjang ke-i dengan jumlah ikan pada selang panjang ke-i; $n_{i}=$ jumlah ikan pada kelas panjang ke-i; $\mathrm{q}_{\mathrm{i}}=1-\mathrm{pi}$; Lm= panjang ikan pertama kali matang gonad

\section{Keterkaitan suhu permukaan laut dengan reproduksi}

Kaitanya suhu permukaan air laut dengan reproduksi ikan dilihat dengan pendekatan korelasi sederhana. Metode ini menurut Suparto (2014), dapat mengetahui hubungan di antara dua variabel, dan jika ada hubungan,bagaimana arah hubungan tersebut. Keeratan hubungan antara satu variable dengan variable yang lain biasa disebut dengan Koefisien Korelasi yangditandai dengan "r". Adapun rumus " $r$ " adalah:

$$
r=\frac{N\left(\sum x y\right)-\left(\sum x \sum y\right)}{\left\{\left(N \sum x^{2}-\left(\sum X\right)^{2}\right)\left(N \Sigma y^{2}-(\Sigma y)^{2}\right)\right\}^{1 / 2}}
$$

Keterangan

$\mathrm{r}=$ nilai koefisien korelasi; $\mathrm{x}=$ nilai variabel pertama; $\mathrm{y}=$ nilai variabel kedua; $\mathrm{N}=$ jumlah data.

\section{HASIL DAN PEMBAHASAN}

\section{Hasil}

Fekunditas adalah jumlah telur yang masak sebelum dikeluarkan pada waktu ikan memijah. Jumlah telur yang terdapat pada ovari ikan kembung lelaki betina (Rastrelliger kanagurta) didapatkan pada TKG 3 dan 4. Hasil pengamatan fekunditas tertinggi pada ikan kembung lelaki sebanyak 96.924 butir dan nilai terendah sebanyak 2314 butir dengan rata-rata 24075 butir telur. Tinggi rendahnya jumlah telur dapat disebabkan karena perbedaan ukuran gonad.

Tingkat kematangan gonad merupakan pengelompokkan kematangan gonad ikan berdasarkan perubahan-perubahan yang terjadi pada gonad. Pada Gambar 2 dan 3 menunjukan tingkat kematangan gonad ikan kembung lelaki jantan dan betina berdasarkan waktu pengamatan.

Indeks kematangan gonad (IKG) dianlisis berdasarka perbandingan dari bobot gonad terhadap bobot tubuh ikan. Nilai IKG rata-rata ikan kembung lelaki jantan dan betina bervariasi pada setiap bulan pengamatan. Berdasarkan Gambar 4 nilai IKG rata-rata ikan kembung lelaki jantan berkisar 0,30-1,35 nilai tertinggi pada bulan September sedangkan pada betina nilai IKG berkisar 0,21-2,59 dan nilai tertinggi pada bulan Juli.

Ukuran pertama matang gonad menunjukan periode panjang yang dicapai matang gonad baik pada jenis kelamin jantan maupun betina. Nilai ukuran pertama kali matang gonad ikan kembung lelaki jantan 193,8 $\mathrm{mm}$ dan betina 177,9 $\mathrm{mm}$.

\section{Pembahasan}

Fekunditas diasumsikan sebagai jumlah telur dalam ovari ikan betina yang mencapai tingkat kematangan gonad III-V (Harianti 2013). Pada setiap individu ikan kembung lelaki betina menghasilkan jumlah telur berkisar pada 231496924 butir dan rata-rata sebanyak 24075 butir. Nilai fekunditas ada hubunganya dengan ukuran ikan, semakin besar atau bobot ukuran ikan maka bobot gonad pun memiliki nilai yang besar

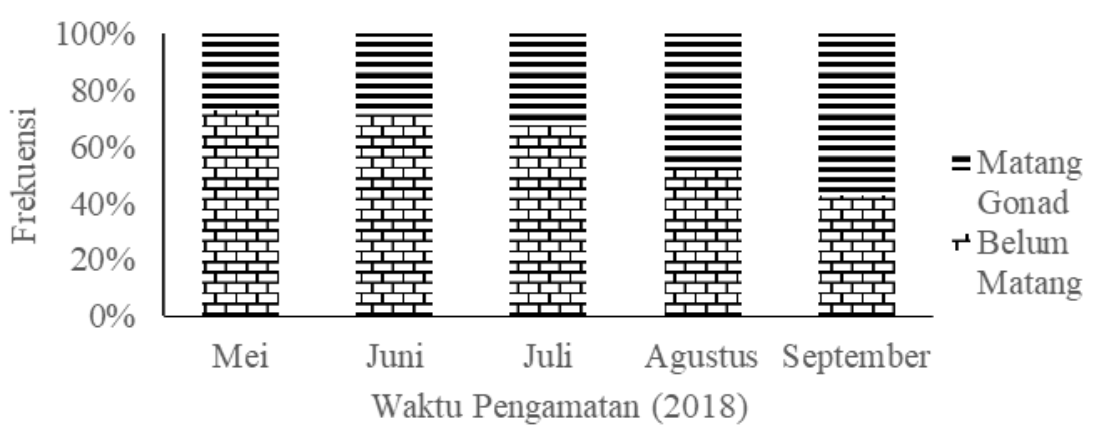

Gambar 2 Tingkat kematangan gonad ikan kembung lelaki jantan

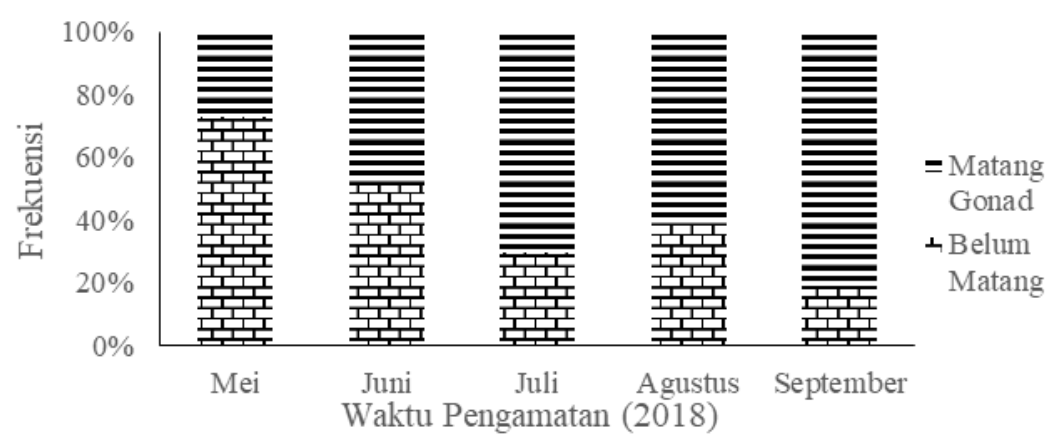

Gambar 3 Tingkat kematangan gonad ikan kembung lelaki betina 


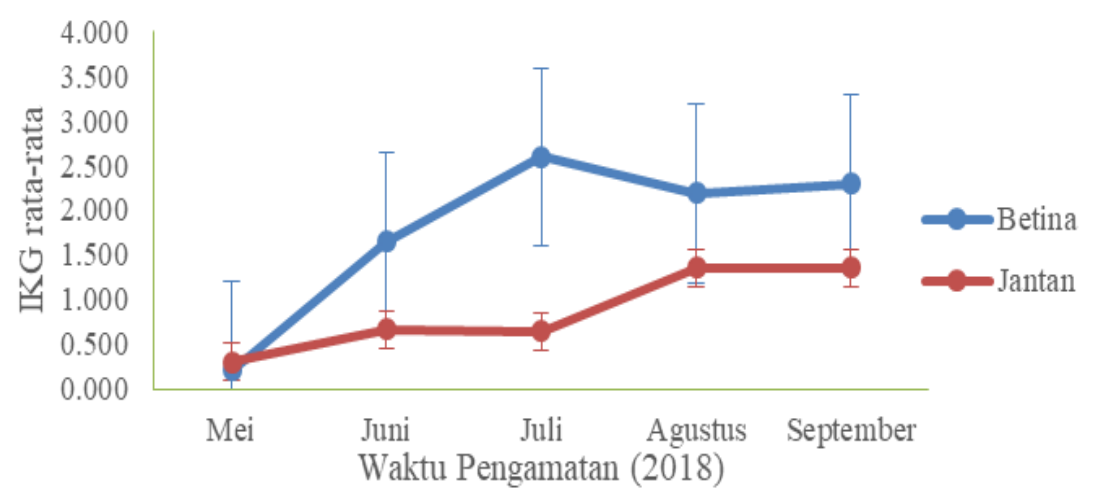

Gambar 4 Indeks kematangan gonad ikan kembung lelaki jantan dan betina

sehingga memiliki jumlah telur yang banyak (Makmur dan Prasetyo 2006). Fekunditas dapat dipengaruhi faktor lingkungan, genetis, ketersediaan makanan, dan juga berkaitan dengan umur ikan. Potensi reproduksi ikan dapat digambarkan oleh kisaran nilai fekunditas (Effendie 2002).

Hasil analisis ukuran pertama kali ikan matang gonad $\left(\mathrm{L}_{\mathrm{m}}\right)$ pada ikan kembung lelaki jantan lebih besar dengan nilai 193,8 mm dibandingkan ikan kembung lelaki betina dengan nilai 177,9 mm. Menurut Abubakar et al. (2019) perbedaan ukuran pertama kali matang gonad pada ikan dapat dipengaruhi oleh kondisi lingkungan yang mengalami perubahan, faktor abiotik, genetik di suatu populasi, kualitas perairan, dan tekanan penangkapan. Apabila ikan tertangkap diatas ukuran pertama kali matang gonad maka dapat memberikan peluang suatu spesies dari kepunahan (Kantun et al. 2015 dalam Kasmi et al 2017).

Sebaran suhu permukaan air laut berdasarkan Gambar 5 menunjukan perbedaan di setiap bulanya hal ini dapat disebabkan oleh faktor kecepatan angin, suhu udara dan fluks panas yang berubah-ubah dan monsun. Variasi nilai suhu permukaan air laut dapat dipengaruhi faktor oseanografi seperti arus dan pasang surut (Tangke et al. 2015). Perubahan suhu permukaan air laut terhadap reproduksi memiliki pengaruh terhadap pengembangan reproduksi ikan, suhu yang rendah dapat merangsang aktivitas reproduksi ikan. Sedangkan kenaikan suhu akan mempengaruhi reproduksi akan tetapi efeknya tergantung pada periode fase pemijahan (Pankhurst dan Munday 2011).

Keterkaitan suhu permukaan air laut dengan parameter reproduksi pada Tabel 2 menunjukan adanya pengaruh terhadap pematangan gonad pada ikan kembung lelaki jantan reproduksi dengan melihat korelasi antara persentase matang gonad dan belum matang gonad menunjukan angka senilai 0,8582 dan 0,7994 . Nilai persentase dari matang gonad semakin tinggi seiring dengan suhu yang semakin turun sedangkan semakin tinggi suhu maka nilai persentase kematangan gonand menunjukan nilai belum matang yang tinggi. Berdasarkan penelitian Saputri (2017) nilai matang gonad (TKG III dan IV) banyak pada bulan Agustus dan September, akan tetapi menurut penelitian Kasmi et al. (2017) menunjukan matang gonad terbanyak pada bulan Juli sampai dengan September. Ukuran pertama kali matang gonad pada ikan kembung lelaki jantan memiliki nilai yang berbeda di setiap bulannya.

Parameter reproduksi ikan kembung lelaki betina terhadap suhu permukaan air laut di perairan Selat Sunda pada Tabel 3 menunjukan adanya pengaruh proses pematangan gonad pada ovarium. Pengaruh suhu terhadap parameter reproduksi pada ikan kembung lelaki betina berdasarkan korelasi nilai matang gonad dan belum matang gonad dengan suhu permukaan laut memiliki nilai 0,9058 dan 0,8790. Menurut penelitian Saputri (2017) dan Kasmi et al. (2017) ikan kembung lelaki betina memiliki matang gonad tertinggi pada bulan Juli sampai dengan September. Nilai ukuran pertama kali matang gonad ikan kembung lelaki betina memiliki nilai yang lebih rendah dari jantan pada bulan Juni, Juli, dan Agustus.

Suhu dapat mempengaruhi ikan selama pemijahan, dan pada perkembangan dan kelangsungan hidup telur dan larva, serta mempengaruhi distribusi, agregasi, migrasi dan perilaku juvenil dan dewasa (Zainuddin et al. 2004). Meningkatnya suhu permukaan air dapat mempengaruhi IKG yang nilainya akan meningkat hal ini diperkuat dengan penelitian (Zaki et al. 2016). Hubungan panjang bobot ikan kembung lelaki yang memiliki pola pertumbuhan yang berbeda dapat dipengaruhi musim dan kondisi lingkungan perairan yang berbeda pada spesies yang sama (Okgermen 2005).

Kemampuan ikan dalam beradaptasi di lingkungan perairan dapat dilihat dari nilai faktor kondisi. Menurut penelitian Okgermen (2005), nilai faktor kondisi ikan kembung lelaki di musim semi berbeda dengan di musim gugur. Eksploitasi spesies yang berlebihan karena tekanan penangkapan yang tinggi dapat menghasilkan stok biomassa yang rendah dan dapat menurunkan nilai ukuran pertama kali matang 

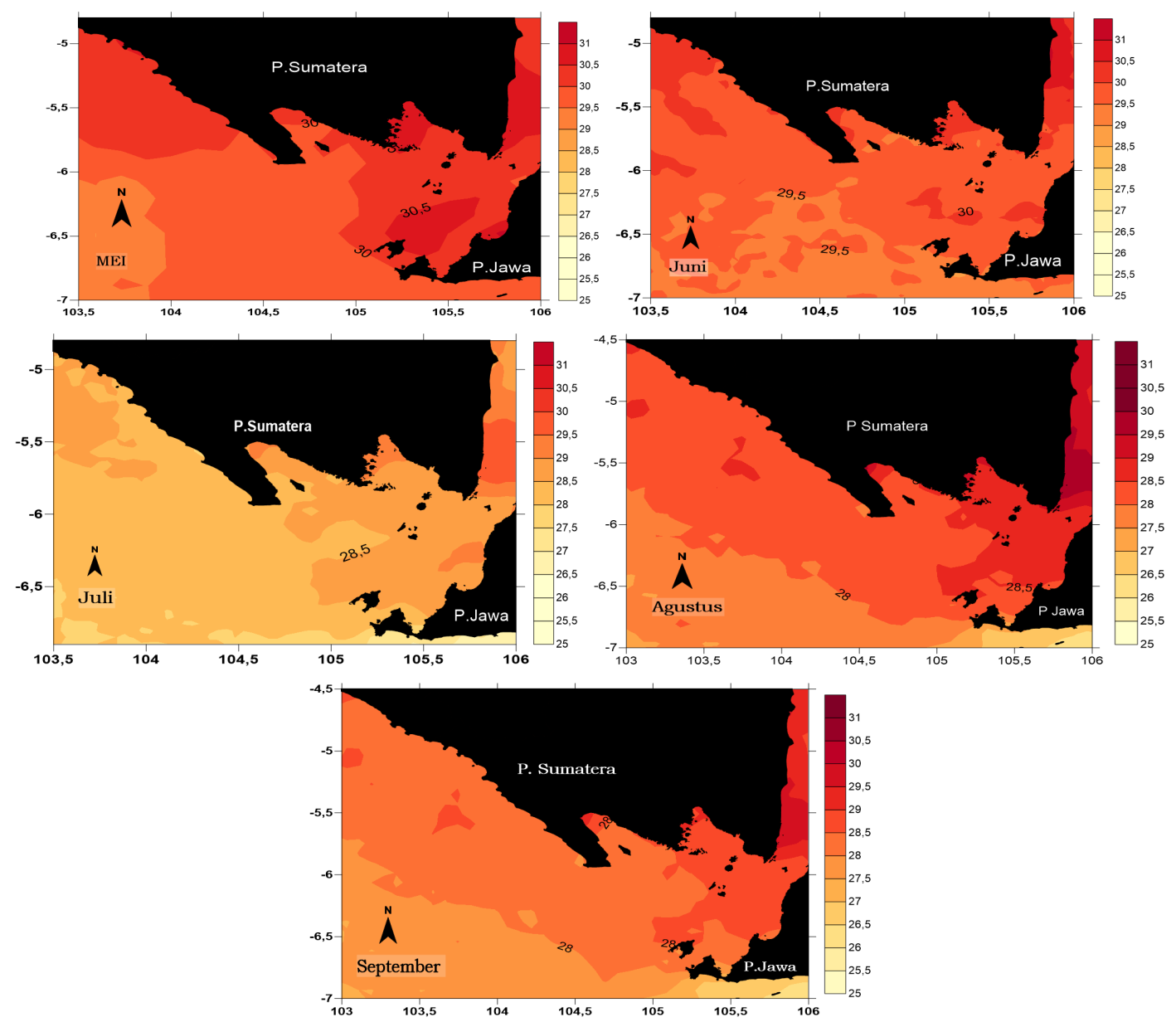

Gambar 5 Suhu permukaan air laut Selat Sunda bulan Mei-September 2018

Tabel 2 Keterkaitan suhu permukaan air laut bulan Mei-September 2018 dengan parameter reproduksi ikan kembung lelaki jantan

\begin{tabular}{lcccccc}
\hline \multicolumn{1}{c}{ Parameter jantan } & Mei & Juni & Wuli & Agustus & September & \multirow{2}{*}{ Korelasi } \\
\hline Belum matang (\%) & 73,02 & 71,43 & 67,24 & 51,61 & 42,59 & 0,7994 \\
Matang gonad (\%) & 26,98 & 28,57 & 32,76 & 48,39 & 57,41 & 0,8582 \\
Rata-rata suhu ( $\left.{ }^{\circ}\right)$ & 30,09 & 29,78 & 28,55 & 28,39 & 28,27 & \\
Lm (mm) & 195,3 & 230,2 & 199,0 & 186,1 & 183,2 & \\
\hline
\end{tabular}

Tabel 3 Keterkaitan suhu permukaan air laut bulan Mei-September 2018 dengan parameter reproduksi ikan kembung lelaki betina

\begin{tabular}{lcccccc}
\hline \multirow{2}{*}{ Parameter betina } & \multicolumn{5}{c}{ Waktu Sampling } & \multirow{2}{*}{ Korelasi } \\
\cline { 2 - 5 } & Mei & Juni & Juli & Agustus & September & \\
\hline Belum matang (\%) & 73,08 & 51,22 & 29,82 & 38,10 & 17,86 & 0,8790 \\
Matang gonad (\%) & 26,92 & 48,78 & 70,18 & 61,90 & 82,14 & 0,9058 \\
Rata-rata suhu ( $\left.{ }^{\circ}\right)$ & 30,09 & 29,78 & 28,55 & 28,39 & 28,27 & \\
Lm (mm) & 201,7 & 173,5 & 194,3 & 176,0 & 187,9 & \\
\hline
\end{tabular}

gonad dan hal ini dapat dikaitkan dengan persediaan makanan (Quaatey dan Marvelias 1999).

Upaya pengelolaan ikan kembung lelaki dari tingginya upaya penangkapan dan permintaan perlu seimbang agar stok ikan tidak terancam menurun. Pengelolaan sumberdaya ikan kembung lelaki di perairan Selat Sunda berdasarkan hasil penelitian ini dengan mengurangi intensitas penangkapan ikan kembung lelaki yang lebih kecil dari ukuran pertama kali matang gonad dan mengatur waktu penangkapan ikan. Ikan yang ukuran nya lebih kecilnya dari nilai ukuran pertama kali matang gonad apabila tertangkap dapat mengurangi potensi ikan untuk reproduksi. Selain itu, pengurangan intensitas penangkapan ikan kembung lelaki di di periode puncak musim pemijahan yang diduga pada bulan Juli dan Agustus. 


\section{KESIMPULAN}

Ukuran pertama kali matang gonad ikan kembung lelaki jantan dan betina senilai 193,8 $\mathrm{mm}$ dan 177,9 mm. Fekunditas ikan kembung lelaki sejumlah 2314-96924 butir telur. Keterkaitan aspek reproduksi ikan kembung lelaki dengan suhu permukaan air laut memiliki pengaruh langsung terhadap individu (biologi) ikan. Pola kematangan gonad ikan selama per 6 bulan dipengaruhi oleh nilai suhu permukaan laut.

\section{TERIMA KASIH}

Pada kesempatan ini kami menyampaikan ucapan terima kasih kepada tim riset selat sunda yaitu Hanif Wafi, Dwi Muninggar, Bisri Mustafa, Zainal Arifin Lubis, Rizal Adha, Sahda Salsabila, dan pimpinan Proyek Penelitian Ristek Dikti Bapak Yonvitner

\section{DAFTAR PUSTAKA}

[NASA] National Aeronautics And Space Administration. 2018. Ocean Color Feature. [internet] [diakses 24 Desember 2018]. Tersedia di https:// Oceancolor.Gsfc.Nasa.Gov/

Abubakar S, Subur R, Tahir I. 2019.Pendugaan ukuran pertama kali matang gonad ikan kembung (Rastrelliger sp ) di perairan Desa Sidangoli Dehe Kecamatan Jailolo Selatan Kabupaten Halmahera Barat. Jurnal Biologi Tropis. 19(1): 42-51

Effendie MI. 2002. Biologi Perikanan. Yogyakarta (ID): Yayasan Pustaka Nusatama.

Ganga U. 2010. Investigations on the biology of indian mackerel Rastrelliger kanagurta (Cuvier, 1817) along the Central Kerala coast with special reference to maturation, feeding and lipid dynamics [thesis]. Cochin University (IN).

Harianti. 2013. Fekunditas dan diameter telur ikan gabus (Channa striata Bloch, 1793) di Danau Tempe, Kabupaten Wajo. Jurnal Saintek Perikanan. 8(2): 18-24

Ibrahim, PS, Setyobudiandi I, Sulistiono. 2018. Hubungan panjang bobot dan faktor kondisi ikan selar kuning Selaroides leptolepis di Perairan Selat Sunda. Jurnal Ilmu Dan Teknologi Kelautan Tropis. 9(2): 577-584

Kasmi M, Hadi S, Kantun W. 2017. Biologi reproduksi ikan kembung lelaki, Rastreliger kanagurta (Cuvier, 1816) di perairan pesisir Takalar, Sulawesi Selatan. Jurnal Iktiologi Indonesia. 17(3): 259-271.

Makmur S dan Prasetyo D. 2006. Kebiasaan makan, tingkat kematangan gonad dan fekunditas ikan haruan (Channa striata Bloch) Di Suaka Perikanan Sungai Sambujur DAS
Barito Kalimantan Selatan. Jurnal Ilmu-Ilmu Perairan Dan Perikanan Indonesia. 13(1): 27 -31 .

Murua H, Kraus G, Saborido RF, Wittames PR, Thorsen A, Junquers S. 2003. Procedures to Estimate Fecundity of Wild Collected Marine Fish in Relation to Fish Reproductive Strategy. Journal of Northwest Atlantic Fishery Science. 33(5): 33-54

Ningrum PV, Ghofar A, Ain C. 2015. Beberapa aspek biologi perikanan rajungan (Portunus pelagicus) di perairan Betahwalang dan sekitarnya. Jurnal Saintek Perikanan, 11(1): 62-71.

Okgermen H. 2005. Seasonal variation in the Length-weight relationship and condition factor of rudd (Scardinius erythrophthalmus L.) in Sapanca Lake. International Journal of Zoological Research. 1(1): 6-10.

Pankhurst NW dan Munday PL. 2011. Effects of climate change on fish reproduction and early life history stages. Marine and Freshwater Research. 62(9): 1015-1026.

Permatachani A, Boer M, Kamal MM. 2016. Kajian stok ikan peperek ( Leiognathus equulus ) berdasarkan alat tangkap jaring rampus di perairan Selat Sunda. Jurnal Teknologi Perikanan dan Kelautan. 7(2): 107 $-116$.

Quaatey SNK dan Maravelias CD. 1999. Maturity and spawning pattern of Sardinella aurita in relation to water temperature and zooplankton abundance off Ghana, West Africa. J. Appl. Ichthyol. 15(1): 63-69

Saputri WE. 2017. Pola pertumbuhan dan reproduksi ikan kembung lelaki (Rastrelliger kanagurta Cuvier, 1817) di perairan Selat Sunda [skripsi]. Bogor (ID): Institut Pertanian Bogor.

Sarasati W. 2017. Dinamika populasi dan biologi reproduksi multispesies ikan kembung ( Rastrelliger faughni, $R$. kanagurta $R$. brachysoma) di perairan Selat Sunda [thesis]. Institut Pertanian Bogor (ID).

Syahailatua A. 2008. Dampak Perubahan Iklim Terhadap Perikanan). Oseana. 33(2): 25-32.

Tangke U, Karuwal JC, Zainuddin M, Mallawa A. 2015. Sebaran Suhu Permukaan Laut Dan Klorofil-a Pengaruhnya Terhadap Hasil Tangkapan Yellowfin Tuna (Thunnus albacares) Di Perairan Laut Halmahera Bagian Selatan. Jurnal Ipteks PSP. 2(3): 248260.

Udupa KS. 1986. Statistical method of estimating the size at first maturity in fishes. Fishbyte. 4 (2): 8-10.

Wang HY. 2014. Effects Of Temperature On Life History Set The Sensitivity To Fishing In Atlantic Cod Gadus morhua. MArine Ecology Progress Series. 514: 217-229. 
Zainuddin M, Saitoh S. 2004. Detection of potential fishing ground for albacore tuna using synoptic measurements of ocean color and thermal remote sensing in the northwestern North Pacific. Geophysical Research Letters. 31(20): 1-4.

Zaki S, Jayabalan N, Al-Kiyumi F, Al-Kharusi L. 2016. Reproductive biology of the Indian mackerel Rastrelliger kanagurta ( Cuvier , 1816 ) from the Mahout coast, Sultanate of Oman. Indian J. Fish. 63(2) 24-32. 